\title{
Arabic Determinative Phrase: DP Movement or Scrambling?
}

\author{
Baseel Ali AlBzour \\ Department of English Language \& Literature, 25113, P.O.Box 130207, Mafraq, Jordan \\ E-mail: nnnbzour@gmail.com
}

Doi:10.7575/aiac.alls.v.6n.5p.87

URL: http://dx.doi.org/10.7575/aiac.alls.v.6n.5p.87
Received: 18/05/2015

Accepted: 24/07/2015

\begin{abstract}
Arabic varieties show explicit linguistic behavior, especially at the syntactic level. This apparent diversity is mainly due to how syntactic rules confine the scope and the flexibility of movement of certain constituents inside and outside their syntactic domains. This paper examines solely how the mother tongue from which all these varieties have emanated, i.e. Standard Arabic can be obviously analyzed as a configurational language that tends to surface in a way similar to nonconfigurational languages at certain surface levels where determinative phrases 'DPs' lend themselves freely to move and result in various templates frequently realized as VSO, OVS, OSV and VOS. These configurational structures seem problematic to construe in many vernacular Arabic varieties, mainly, in Suburbanite Northern Jordanian Arabic because of the scarcity of effective inflectional morphology such varieties exploit rather than pragmatic factors.
\end{abstract}

Keywords: Configurational, non-configurational; determinative phrase; template; movement; inflections; constituents

\section{Introduction}

Arabic, the researcher's native language, is one of the major Semitic language, so it goes without saying that it shares many features with a bunch of dead or recently revived languages such as Hebrew, Acadian, Mesopotamian, and Aramaic. It's axiomatic, therefore, that such languages are morphologically rich languages par excellence; thus, their grammars and even pragmatics do frequently overlap in a subtle manner. Hundreds of vernacular dialects are deeply rooted and prevalent in the Arab World. Standard Arabic is a common denominator that all Arab countries have in common since it is the language of their Holy Book, official education, legal jargon as well as the innumerable space channels and other means of mass media. Evidently, there are half a dozen of major dialects in Jordan, the researcher's homeland.

Syntactic structures of Jordanian Arabic and Standard Arabic meet at certain points and show radical contrast oftentimes. To narrow the scope of the current research, this paper in principle aims at shedding light on some fundamental aspects of syntactic assumptions and their implementation as well as implications vis- $a$-vis Arabic determinative Phrases (henceforth DPs), more specifically whether such DPs technically undergo a process of movement or scrambling in the final analysis (see Larson 1988, Kayne 1994). This may trigger a need to hold some contrastive analysis between Arabic DPs and English ones when divergence substantially occurs. The data of this paper owes specific reference to both Standard Arabic (SA) and Suburbanite Northern Jordanian Arabic (SNJA), since the researcher strictly claims she is a native speaker of both. A review of the current relevant literature is briefly carried out to investigate the state of affairs of such movement/scrambling processes to see if there is any syntactic evidence that may trigger such a phenomenon and/ or if there is some more intricate pragmatic and morphological interface that may best support the analysis of the data (cf., Andrews 1996, N. Albzour 2015, et al).

It has been the prime concern of linguists, in general, and syntacticians, in particular to account for a universal premise that may best describe language under a unified universal umbrella despite the substantial differences among world languages. This linguistic interest has crucially crystallized since Chomsky set the distinct features of such universal grammar in his ambitious enterprise Syntactic Structures in 1957 and all through the past five decades where different complementary and sometimes clashing theories have emerged to solve the riddle that Chomsky spurred because this loose word grammar "is often extended in Chomskyan theories to encompass the whole knowledge of language in the individual's mind" (Cook \& Newson 2007: 7). Hence, it is quite legitimate to further extend our perspective to cater for any potentially linguistic oriented analyses whether it be syntax, semantics, morphology or pragmatics in our ultimate quest for such a Chomskyan paradigm of grammar to annul any scrambling scenarios (Grewendorf and Sternefeld 1990). Consequently, this begs the question of the feasibility and the necessity of applying such generative theories to languages such as Arabic though substantially parametrical factors explicitly intervene.

\section{Scope of the Study \& Data Validity}

We might expect that a language's sentence-structure and word-structure should mesh rather straightforwardly. For instance, if the syntax of a particular language distinguishes different arguments of the verb, and the morphology distinguishes different cases, it seems natural to assume that the two systems will line up. In real languages the situation is often more complex (Bearman, 2005:1). 
The argument over the DP and the NP seems one of the most heated topics that syntacticians have debated. Within the framework of X-bar theory, it was not until Abney (1987) that a cogent argument was presented in favor of DP hypothesis where the determiner is deemed as the head of the nominal phrase rather than the noun i.e. the noun is considered a head of the complement to the determiner. As a point of departure, we will assume that Arabic lends itself to the DP hypothesis at this level because any controversial argument relevant to this DP vs. NP distinction would seem futile at this stage as far as the scope of this paper may encompass in this very limited space.

To gradually develop this analysis, the researcher follows Carney's (2007) constituency tests in order to illustrate the entity of DP and NP in Arabic as a basic constituent through applying some basic syntactic tests to the following MSA example (1). To be consistent in her analysis at this earlier stage, the researcher will adopt one template, i.e. SVO rather than VSO which is permissible too in MSA, though controversially presented and argued for. The researcher has to note that each Arabic sentence is thoroughly glossed underneath. In addition, two English translations are provided: one is word for word-which is marked with an asterisk when ungrammatical as it is the case in most examples; the other translation is an idiomatic English rendition.

(1)

ha?ulaa? $\quad$ I $\quad$ Tal $\quad \mathrm{u} \quad$-nubaha? $\mathrm{u}$

D/MascPl These Phon/M Def/D the N/Pl student Nom/M A/Pl/Masc bright Nom.Ag

*These the students bright.

These students are bright.

I. Hypothesis: ha? ula? $\boldsymbol{i}$ and $\boldsymbol{a l}$ are determiners.

Test 1: Assumption: D's can precede the NP's.

\section{Exemplification:}
a. ha?ulaa?i Tullabun
nubaha?u .
D/Pl These IDef N/Pl student
Nom/M bright

Those are bright students
b. al-
Tullabu
al- nubaha? u
sawfa ya9maloona
D/ The N/Pl student
D THE A-bright Nom/M
Mod will
V/Prs work $\mathrm{Ag}+\mathrm{T}$

The bright students will work.

Output: Positive D's can precede the noun Tullabu.

Test 2: Assumption: D's can inflect for number.

Exemplification:

$\begin{array}{llllllll}\text { HaTHa } & \text { ?al- } & \text { Talib } & \boldsymbol{u} & \text { sawfa } & \text { ya9mal u } & \\ \text { D/Sg/Masc } & \text { D-the } & \text { N/Sg student Nom/M } & \text { Mod will } & & \text { V/Prs work } & \text { Ag+T }\end{array}$

*This the student will work.

This student will work

Output: Positive: D's can inflect for number.

Test 3: Assumption: Demonstrative D's can precede Definite D's in Arabic, unlike English.

Exemplefication:

ha?ula? al- Tullab $u \quad$ sawfa ya9maluna

D/ PlThese D-the N/Pl student Nom/M Modwill V/Prs work Ag+T

*These the students will work.

These students will work.

Output: Positive: D's can precede another D.

Conclusion: Based on these three tests, the hypothesis that ' ha? ula? i and al are determiners' is right.

\section{Hypothesis: Tullab is a noun.}

Test 1: Assumption: NP's can be preceded by a vocative particle in vocative sentences/phrases.

Exemplification:

$\begin{array}{llllll}\boldsymbol{y} \boldsymbol{a} & \boldsymbol{T a l i b} & \boldsymbol{u} & \text { i9mal al- wajib } & \text { a }\end{array}$

$\begin{array}{lllll}\text { Voc. Part } & \text { N/Sg student } & \text { Nom/M } & \text { V/Imp work } & \text { D. the assignment } \quad \text { Acc. M }\end{array}$


* Hey student, work the assignment.

Hey student, work on the assignment.

Output: Positive: NP's can be preceded by a vocative particle.

Test 2: Assumption NP's can inflect for number (a. singular, b. dual \& c. plural)

Exemplification:

a. haTHa al- Talib $\boldsymbol{u}$ sawfa ya9mal u

D/SgThis D-the N/Sg student Nom/M Mod will V/Prs work $\mathrm{Ag}+\mathrm{T}$

* This the student will work

This student will work.

b. haTHan al- Talib an sawfa ya9mal an

D/ Dual These D-the N/Dual students Nom/M Mod will V/Prs work Ag+T

* These the two students will work.

These two students will work.

c. ha?ula?i al- Tullab $\boldsymbol{u}$ sawfa ya9mal oona .

D/ Pl These D-the N/P1 students Nom/M Mod will V/Prs work Ag+T

*These the students will work.

These students will work.

Output: Positive: N's can inflect for number.

Test 3: Assumption: NP's can inflect for gender

Exemplification:

a.haTHihi al- Talibat $\boldsymbol{u}$ sawfa $\mathrm{t}^{+}$a9mal $u$ u.

$\mathrm{D} / \mathrm{Sg} / \mathrm{Fem}$ This D-the N/Sg/Fem student Nom/M Mod will Fem/ V/Prs work Ag+T

* This the student will work.

This student will work.

$\begin{array}{lllllll}\text { b.haTHa } & \text { al- } & \text { Talib } & \boldsymbol{u} & \text { sawfa } & \mathrm{y}+\mathrm{a} 9 \mathrm{mal} & \mathrm{u}\end{array}$

$\mathrm{D} / \mathrm{Sg} / \mathrm{MascThis} \mathrm{D}$-the N/Sg/Masc student Nom/M Mod will Masc/V/Prs work $\mathrm{Ag}+\mathrm{T}$

*This the student will work.

This student will work.

Output: Positive: NP's can inflect for gender.

Test 4: Assumption: N's can inflect for case (a. nominative, $b$. accusative and c. genitive).

Exemplification:

a.Subject:

al- Tullab- $\boldsymbol{u}$ sawfa ya9mal oon a .

D The N/P1/Masc students Nom/M Mod will Masc/V/Prs work $\mathrm{Ag}+\mathrm{T}$

The student will work.

b. Object of verb/V-Complement:

Ra?ayt $\boldsymbol{u}$ al- Tullab- $\boldsymbol{a}$ ya9mal oon a.

V/Pst saw Nom/M-I D The N/Pl/Masc students Acc./M Masc/V/Prs work Ag+T

I saw the students working.

c. Object of a prep/P-Complement:

Qult $u$ li al- Tullab- $\boldsymbol{i}$ ? an ya9mal oo.

V/Pst said Nom/M-I p. to D The N/PI/Masc students Gen.M Inf. to Masc/V/Prs work Ag+T

I told the students to work.

Output: Positive: NP's can inflect for case. 
Test 5: Assumption: N's can be post modified by adjectives.

Exemplification:

haTHa al- Talib $\boldsymbol{u}$ al- THakiyy $\boldsymbol{u}$ ya9mal u .

D This D the N/Sg/Masc Nom/M D the A/Masc clever Nom.M Masc/ V/Prs work Ag+T

*This the clever student works.

This clever student works.

Output: Positive: NP's can be post modified by adjectives.

Conclusion: Based on these four tests, the hypothesis that 'Tullab is a noun' is right.

III. Hypothesis: nubaha? is an adjective.

Test 1: Assumption: AP's can inflect for number (a. singular, b. dual \& c. plural), so they agree with the $N$ they modify at these three levels.

Exemplification:

a. haTHa al- Talib u al- nabeeh $u$

D/Masc This D the N/Sg/Masc student Nom/M D- the A/Masc bright Nom. M.

*This the bright student.

This is the bright student.

b. haTHan al- Talib an al- nabeeh an

D/Dual/Masc These D the N/Dual/Masc students Nom/M D the A/Dual Masc bright Nom.M

* These the two bright students.

These are the two bright students.

c. ha?ula?i al- Tullab u al- nubaha? u.

D/P1/Masc These D the N/P1/Masc students Nom/M D the A/P1 Masc bright Nom.M

*These the bright students.

Output: Positive: AP's can inflect for number.

Test 2: Assumption: A's can inflect for gender (masculine and feminine), so they agree with the N's they modify at these two levels.

Exemplification:

a. haTHa al- Talib a al- nabeeh

$\mathrm{D} / \mathrm{Sg} / \mathrm{Masc}$ This $\mathrm{D}$ the N/Sg/Masc student Nom/M D the A/Sg Masc bright Nom.M

* This the bright student.

This is the bright student.
b. haTHihi
al- Taliba
$\boldsymbol{u}$
al- nabeehat
$\boldsymbol{u}$.

$\mathrm{D} / \mathrm{Sg} /$ Fem This $\mathrm{D}$ the N/Sg/Fem student Nom/M D the A/Sg. Fem bright Nom.M

* This the bright student.

This is the bright student.

c. hatani al- Talibat an $i$ al- nabeehat an

D/Dual/Fem These D the N/Dual/Fem students Nom/M Phon D the A/Dual. Fem bright Nom.M

* These the two bright students.

These are the two bright students.

Output: Positive: AP's can inflect for gender.

Test 3: Assumption: AP's can post-modify N's.

Exemplification:

haTHa al- Talib u al- nabeehu-

D/Sg/Masc This D the N/Sg/Masc student Nom/M D the A/Sg. Masc bright Nom.M

*This the bright student . 
This is the bright student.

Output: Positive: AP's can post modify N's.

Test 4: Assumption: AP's can be inflected for comparative and superlative (more/most + nominal root).

Exemplification:

haTHa al- Talib u al- akthar $\boldsymbol{u}$ nabahat an

D/Sg/Masc This D the N/Sg/Masc student Nom/M D the SupA. Most. Nom.M Nomin.R brightNESS Nom.M

*This the student is the brightest.

This student is the brightest.

Output: Positive: AP's can be inflected for comparative and superlative (more/most + nominal root).

Test 5: Assumption: A's can follow a linking verb yabdoo"seem/look" or the copula Be, which has null form in the present tense unlike the future and the past. A distinction is made in traditional grammar since the word 'nabeeh/bright' takes an accusative case in (a) and (c) while it takes a nominative case in (b), so it seems the Null constituent does not qualify to assign case to the following A' unlike the overt counterparts.

Exemplification:

a.haTHa al- Talib u yabdoo nabeeh an.

D/Sg/Masc This D the N/Sg/Masc student Nom/M V/Pres.seems A/Sg Masc bright Nom.M

*This the student seems bright.

This student seems bright.

b.haTHa al- Talib u (Null Copula) nabeeh un.

D/Sg/Masc This D the N/Sg/Masc student Nom/M V/Pres.Null A/Sg Masc bright Nom.M

*This the student bright.

This student is bright.

c.haTHa al- Talib $u$ kan a nabeeh an.

$\mathrm{D} / \mathrm{Sg} /$ Masc This D the N/Sg/Masc student Nom/M V/Pst Masc.Morph A/Sg Masc bright Nom.M

*This the student was bright

This student was bright.

Output: Positive: follow a linking verb yabdoo"seem/look" or the copula be. Conclusion: Based on these five tests, the hypothesis that ' nubaha? is an adjective' is right.

\section{Results and Analysis}

Thus far, we have illustrated the syntactic identity of Arabic DPs in broad terms to prove how such a constituent can be handled within the same generative perspective that English DPs can be perceived though some parametrical mismatches inevitably surface (Marantz 1995). However, the need arise to deeply explore another significant aspect that crucially strikes distinction between Standard Arabic vs. English, on the one hand, as well as Standard Arabic vs. Jordanian Arabic, on the other hand, i.e. how inflections operate surface. These two varieties of Arabic operate differently to a great extent in exploiting inflectional morphemes due to the basic distinctive role of morphological markers which evidently and subtly exist to presumably mark every single word in terms of gender, number, tense and case in SA unlike SNJA and many other vernaculars, (see N. AlBzour 2015).. The first two examples (a) and (b) demonstrate this inflectional gap that exists between the standard and the vernacular version as in (c) and (d) where agreement, tense, number and gender are almost absent in SNJA unlike SA.

(2)

a. nam - (a) pro albariHat (a)

slept T. Mark (HE) yesterday case

He slept yesterday.

b. nam - (a- a) albariHat (a)

slept PstT. Dual (They) yesterday case

They (two) slept yesterday.

c. nam u - imbariH

slept PstT. PI yesterday

They ( two or more) slept yesterday. 
d. nam $u$ - (u) albariHat (a)

slept PstT. Pl (They) yesterday case

(SA)

They slept yesterday.

In addition, these morphological distinctions give rise to the null finite subject in SA i.e. little pro, which is so prevalent and unequivocally recognized in terms of gender and number because it only occurs with the singular (feminine or masculine). The significant relevance of this pro is its crucial role in demarcating the binding domain of the DP as it will be thoroughly examined at a later stage/

DPs can occur in a nominative case or in the accusative form, i.e. either as subjects of the VP or as complements of transitive verbs in VPs or complements of prepositions in PPs as in (3):

(3)

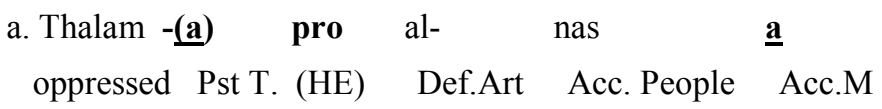

He oppressed people.

b. Thalam - pro al- nas

oppressed (HE) Def.Art Acc. People

He oppressed people.

c. Huw (a) mu9tadd (un) b(i) nafs $\underline{\mathrm{i}}$ h (i)

He NomM. too Proud Nom Mar with self Acc him

He is too proud of her.

d. Huw mi9tadd fee ha

(NJA)

He too proud in her

He is too proud of her.

Bearing in mind the binding domain as it has been thoroughly discussed by many syntacticians such as Chomsky, (1981), Haegeman (1991), Radford (2004), Carnie (2007), we may realize that such morphological distinctions have undeniable bearings in SA as opposed to their counterparts in SNJA. This is the secret of the flexible word order in SA.

(4)

a. Shatam -a proi $\quad[$ Nafs- a - hu]i

cursed he (3.Sg.M) self-acc. mark- his

Hei cursed himselfi

b. shatam -at proi [Nafs- a ha]i

cursed she(3.Sg.F) self - acc. mark- her

Shei cursed herselfi

c. shatam- aai [aNfus- a- hum a]i

cursed (M.dual) self acc,mark their

Theyi cursed themselvesi.

d. shatam u - ui [anfus- a $\quad$ hum]

cursed (3.pl.M) selves acc.mark their

Theyi cursed themselvesi

In accordance with the Locality Principle, this explains how Principle A of the Binding Theory (BT) stipulates that an anaphor be bound in its local domain or governing category, unlike Principle B where personal pronouns must be free in their domain. Of course, the binding domain of a DP anaphor is the lowest clausal node dominating it, i.e. the (TP). As a result of this morphological hiatus between SA and SNJA, it must be noted that any word order resulting from DP movement or scrambling (so far no distinction has been made) in SA is quite grammatical, while any equivalent word order in SNJA is deemed ungrammatical as in (5.a) and (5.b), respectively because the subject-object DPs can be easily discerned in SA by virtue of the nominative vs. accusative morphemes:

(5)

a. Nafs- a - hu]i shatam-a alTalib- u i

self-acc. mark- his cursed the student.Nom.M

The studenti cursed himselfi 


\section{b. *Nafsuh ji shatam elSabiy}

SNJA

self-- his cursed the student.Nom

The studenti cursed himselfi

It can be hard evidence for such morphological role when the case marker is obligatorily absent in SA due to phonological constraints that precludes the overt phonological form of the nominative and the accusative case as it can be seen in (6):

(6)
a. Eisa
shatam-a
Mousa
Prop.Name.Nom. cursed Prop.Name Acc.
Eisa cursed Mousa
b. * Eisa curse-a Mousa
Prop.Name. Acc. cursed Prop.Name Nom.

SA

*Mousa cursed Eisa

The subject-object DPs can be by no means discerned in SA by virtue of the nominative vs. accusative morphemes because they are phonologically absent, so a default Subject-Object reading is permissible, i.e. the first DP must be the one in the nominative case and the second DP is the one in the accusative case, so the absence of morphology in SA in this unique case explains why NJA, similar to English, can not allow such a flexible movement that exists in SA more often than not. Furthermore, this morphosyntactic interface in SA is of paramount importance in reflecting the significance of binding and trace as well as theta role since the trace of the reflexive, for example, in (7.d) prohibits any DP to take its theta role as opposed to (7: a-c):

(7)

a. shatam-a alTalib-u i Nafs- a - huli

cursed the student.Nom self - acc. mark- his

The studenti cursed himselfi

b. alTalib-ui shatam-a Nafs- a - hu]i

the student.Nom cursed self - acc. mark- his

The ladi killed himselfi

c.[Nafs- a - hu]i shatam-a ti alTalib-ui

self - acc. mark- his cursed the student.Nom

The studenti cursed himselfi

d. *[Nafs-a - hu]i shatam-a proi [t alTalib-ai]

self - acc. mark- his cursed the student.Acc

himselfi cursed the studentj

The significance of SA Arabic rich morphology can be seen more evident in the fact that it licenses topicalization at a wide range even when applied to anaphors, which are so sensitive to locality as it can be seen in (8: a-d):

(8)

a.[Nafs- a - hu]i shatam -a pro i

self - acc. mark- his cursed he (3.Sg.M)

Hei cursed himselfi

b.[Nafs- a ha]i shatam -at pro $\mathbf{i}$

self - acc. mark- her cursed she(3.Sg.F)

Shei cursed herselfi

c. [anfus- a- hum a]i shatam- aai

self acc,mark their cursed (M.dual)

Theyi cursed themselvesi.

d. [anfus- a hum]I shatam - ui

selves acc.mar their cursed (3.pl.M)

Theyi cursed themselvesi. 
The major issue at this point is to decide here whether such DPs undergo movement or whether it is just a matter of scrambling. This might be intriguing when all the utterances have or might appear to have exactly the same meaning when interpreted as the subject. SA at a certain level resembles languages like Warlpiri (see Hale 1983), where grammatical functions such as subject and object may not necessarily be defined by the phrase structure. Instead, the subject and the object in the sentence can be decided by marking of case or agreement or sometimes both. For example, the subject in Warlpiri can be marked with the ergative case marker (-'ngku'), which is used to mark subjects in ergative languages; in SA the case marker ' $u$ ' satisfies such a grammatical function. This supports how rich morphology in SA is an example of a tendency for languages with rich morphological marking to be able to have less restricted word orders, whereas languages with poor morphology tend to have strict hierarchical phrase structures (Bresnan 2001: 6).

Such an argument of Nonconfigurationality suggests that grammatical relations may be encoded in the shape of words, rather than in phrasal structure. The possibility of encoding function through words or phrases (or both) underlies the LFG design (Bresnan 2001: 6). It distinguishes it from frameworks such as P\&P where the notion of subject and object is defined structurally (the object is the DP occupying the specifier of IP and the object is the DP occupying the complement position of the verb (Baker 2001: 209). Broadly speaking, LFG can account for nonconfigurationality by encoding information about grammatical relations such as subject and object in f-structure rather than in c-structure (Austin and Bresnan 1996).

However, the researcher would argue that DPs in SA show a tendency for systematic syntactic movement with (1) a discourse motivation, (2) morphological license and (3) syntactic landing site as it might be fairly acceptable in the assumption advocated by Rizzi (1997) and Radford (2004). They posit that topicalization is a kind of A-bar movement, so the DP occupies the SPEC position within the Topic Phrase. A rational piece of evidence for DP movement within the CP is if we consider Wh-Question in Arabic since the Force node is in a position higher than the Focus node; that is why the reflexive is allowed to move freely within the $\mathrm{CP}$ and below the ForcP, and so moving the DP outside the ForcP results in an ungrammatical sentence, (See N. Albzour 2015). On the other hand, the absence of such morphosyntactic interface proscribes any similar syntactic constructions in SNJA as it can be clearly seen in (9: a-c) where such movements turn to be ungrammatical:

(9)

$$
\begin{aligned}
& \text {.a.* [Nafs- uh]i shatam - pro i } \\
& \text { self - his cursed he (3.Sg.M) } \\
& \text { Hei cursed himselfi } \\
& \text { b.*[Nafis- ha]i shatam -at proi } \\
& \text { self - her cursed she(3.Sg.F) } \\
& \text { Shei cursed herselfi } \\
& \text { c.?* [anfus- - hum ]i shatam- uui } \\
& \text { self their cursed (M.PL/Dual) }
\end{aligned}
$$

Theyi cursed themselvesi.

\section{Conclusion}

Syntactic structures and syntactic operations can be misleading if analyzed without attentive awareness of the underlying motivations that stimulate and restrict basic syntactic movements. Such movements can be misconceived if only traced on simplistic and excusive syntactic grounds. Standard Arabic is one of the problematic languages in which various motivations can conspire to guarantee the grammaticality of such surfacing structures because SA is a configurational language that behaves similar to nonconfigurational languages only at surface levels. SA is an SVO language although other templates frequently surface, so VSO, OVS, OSV and VOS are fair choices. The VSO template is not a result of ' $\mathrm{V}$-to-T' movement only as Benmamoun (2000) argues; rather it is a result of morphological guarantors underlyingly and projected for topicalization reasons at the phonological form, similar to all other aforementioned templates. Therefore, a huge spectrum of 'movement' realization and word order can be observed in SA as a result of the subtle morphological role. However, the lack of such inflectional morphology in SNJA precludes such overt flexibility. The motivation behind DP movement in Arabic is morphosyntactic rather than pragmatic per se as explicitly maintained by N. Albzour (2015).

\section{Here is key list for abbreviated terms used in glossing:}

\section{A: Adjective.}

2. AP: Adjective Phrase.

3. Acc: Accusative.

4. Adv: Adverb.

5. Ag: Agreement.

6. Aux: Auxiliary. 
7. D: Determiner.

8. Fem: Feminine.

9. Gen: Genitive.

10. I-Def: Indefinite.

11. Imp: Imperative.

12. Inf: Infinitive.

13. M: Marker.

14. Masc: Masculine.

15. Mod: Modal.

16. Morph: Morpheme.

17. N: Noun

18. Nom: Nominative.

19. Nomin R: Nominal Root.

20. NP: Noun Phrase.

21. P: Preposition.

22. Part: Particle.

23. PI: Plural.

24. Phon M: Phonological Marker.

25. Prs: Present.

26. Pst: Past.

27. Sg: Singular.

28. Sup: Superlative.

29. T: Tense.

30. V: Verb.

31. Voc: Vocative.

\section{References}

Abney, S. P. (1987). The English Noun Phrase in its Sentential Aspect. PhD. MIT.

AlBzour, Na. (2015). Arabic anaphora: Discourse subduing morpho-syntactic interaction. English Language and Literature Studies, 4(3).

Andrews, A. D. (1996). Semantic case-stacking and inside-out unification. Australian Journal of Linguistics, 16(1):155.

Austin, Peter K. and Joan Bresnan. (1996). Nonconfigurationality in Australian aboriginal languages. Natural Language and Linguistic Theory,14(2):215-268.

Baker, M.C. (2001). The Natures of nonconfigurationality. In Mark Baltin and Chris Collins (Eds.). The handbook of contemporary syntactic theory. Oxford: Blackwell Publishing Ltd. 407-438.

Bearman, M., Brown, D., and Greville, C. (2005). The Syntax-Morphology Interface. Cambridge: Cambridge University Press.

Benmamoun, E. (2000). The Feature Structure of Functional Categories: A comparative study of Arabic dialects. Oxford: Oxford University Press.

Bresnan, J. (1994). Locative inversion and the architecture of universal grammar. Language, 70,72-131.

Bresnan, J. (2001). Lexical-Functional Syntax. Oxford: Blackwell Publishers Ltd.

Chomsky, N. (1957). Syntactic Structures: The Hague: Mouton.

Chomsky, N. (1981). Lectures on Government and Binding. Dordrecht: Foris.

Chomsky, N. (1995). The Minimalist Program. Cambridge: MIT Press.

Cook, V. J. and Newson, M. (2007). Chomsky's universal grammar. Blackwell: Blackwell Publishing.

Cooper, R. P. (1996). Head-driven Phrase Structure Grammar. In K. Brown and J. Miller (Ed.), Concise Encyclopedia of Syntactic Theories. Oxford: Pergamon. 191-196.

Grewendorf, S., and Sternefeld, W. (Eds.). (1990). Scrambling and Barriers. Amsterdam: Benjamins.

Haegeman, L. (1991). Introduction to Government and Binding Theory. Oxford: Blackwell Publishing. 
Hale, K. (1983). Warlpiri and the grammar of nonconfigurational languages. Natural Language and Linguistic Theory, $1,5-47$.

Kayne, R. (1994). The antisymmetry of syntax. Linguistic Inquiry Monograph 25. MIT Press.

Larson, R. (1988). On the double object construction. Linguistic Inquiry, 19, 335-392.

Mahmoud, M. (2000). Word Order, Agreement and Pronominalization in Standard and Palestinian Arabic. John Benjamins Publishing.

Marantz, A. (1995). The Minimalist Program. In Gert Webelhuth (ed.), Government and Binding Theory and the minimalist program. Cambridge, MA: Blackwell Publishers. 349-382.

Napoli, Donna Jo. (1993). Syntax: Theory and Problem. Oxford: Oxford University Press.

Radford, A. (2004). Minimalist syntax. Cambridge: Cambridge University Press.

Rizzi, L. (1997). 'The Finite Structure of the Left Periphery. In L. Haegeman (Ed.), Elements of Grammar. Kluwer: Dordrecht. 281-337. 